\title{
CULTURA POLÍTICA, CAPITAL SOCIAL E PERCEPÇÕES SOBRE CORRUPÇÃO: UMA INVESTIGAÇÃO QUANTITATIVA EM NÍVEL MUNDIAL ${ }^{1}$
}

Timothy J. Power

\author{
Júlio González
}

\begin{abstract}
RESUMO
Nos anos 1990, teóricos do capital social passaram a estabelecer uma conexão direta entre cultura política e desempenho de instituições governamentais. Se tal relação causal existe, então deve ser possível identificar fatores culturais associados à corrupção. Neste artigo testamos essa hipótese em nivel mundial. Usando métodos quantitativos, desenvolvemos uma série de modelos multivariados que visam medir o efeito de fatores culturais - tais como tradição religiosa, confiança interpessoal e obediência às leis - sobre o nível de corrupção em vários países, usando a avaliação reputacional da organização não-governamental Transparência Internacional como a variável dependente. O artigo mostra que o nível de corrupção em um determinado país é essencialmente uma função do tipo de regime político e do nivel de desenvolvimento econômico. Entretanto, algumas características culturais agregam poder explicativo aos modelos, contextualizando as interpretações macroeconômicas e macropolíticas da corrupção.
\end{abstract}

PALAVRAS-CHAVE: corrupção; capital social; cultura política; democracia; World Values Surveys; Transparência Internacional.

\section{INTRODUÇÃO}

Este dossiê sobre Cultura Política concentrase simultaneamente na democracia e no desenvolvimento, promovendo um diálogo provocativo entre os estudiosos de ambos os fenômenos. Ainda que as questões sejam variadas e o debate de largo alcance, há uma questão em torno de que há um consenso substancial a respeito da democracia e do desenvolvimento: a corrupção é prejudicial para ambos. Será que a ótica da cultura política e a teoria do capital social podem ensinarnos algo sobre o fenômeno da corrupção?

O debate sobre a corrupção, que é normalmente definida como o uso de bens públicos para fins privados, normalmente conduz a certas proposições freqüentemente repetidas. Nesse sentido, fica fácil para certos especialistas, dedicados ao estudo de um só continente ou de algum país que considerem uma excepcionalidade regional, ver a corrupção como uma questão de "cultura", das coisas serem feitas de maneira "diferente" no país "X" ou na região "Y", e assumir

\footnotetext{
1 Tradução de Marília Gomide Mochel.
}

que o comportamento corrupto é comum nas sociedades em desenvolvimento. No entanto, se isso for verdade, pode-se perguntar por que virtualmente todas as formas de corrupção são proibidas em quase todos os países (KLITGAARD, 1988; 1998) ou por que a corrupção parece estar florescendo nas sociedades industriais avançadas. Na verdade, escândalos de corrupção abalaram recentemente governos na Itália, Grã-Bretanha, Japão, Alemanha e Estados Unidos. Claramente, como apontado por Klitgaard (1988, p. 10), "há evidências de que algumas formas de comportamento corrupto estão crescendo atualmente nas nações mais 'avançadas' política e economicamente".

Ouve-se com freqüência que a tendência global em direção à democracia política, por aumentar a "transparência" na vida pública, reduzirá o espaço político disponível para práticas corruptas. De modo similar, outras pessoas defendem que o neoliberalismo e o enxugamento do Estado, ao reduzir o conjunto de recursos estatais dos quais os funcionários corruptos podem beneficiar-se, terão o mesmo efeito. No entanto, estudos recentes deixam poucas dúvidas de que a corrupção parece ter aumentado em alguns países apesar de transições em direção ao liberalismo econômico e 
político: Hessel e Murphy (2000) encontraram evidências que sugerem que a corrupção parece estar crescendo nos países ex-comunistas depois da instalação de regimes democráticos e de economias de mercado. Desse modo, ainda que alguns pesquisadores tenham permitido que seu "seus" países ou regiões são casos excepcionais, a corrupção dificilmente é um problema exclusivo dos países em desenvolvimento ou das economias em transição. Na verdade, nenhum país no mundo foi poupado de seus efeitos nefastos (NDIAYE, 1998).

É claro que a incidência de corrupção varia enormemente entre as sociedades, de rara até sistemática, com alguns países em desenvolvimento tendo menos incidentes com corrupção do que algumas nações desenvolvidas. Por outro lado, a pesquisa comparada sugere que as práticas corruptas são geralmente mais difundidas e mais sistematicamente enraizadas em várias partes do mundo em desenvolvimento do que no Ocidente industrializado (KLITGAARD, 1988). Essa generalização levanta três pontos. Em primeiro lugar, sugere que a corrupção pode ser mais endêmica nos países pobres, nãodemocráticos ou politicamente voláteis. Segundo, conduz-nos a questionar se os atributos culturais podem de fato explicar ao menos uma parte da variação no nível de corrupção entre e dentro das regiões do mundo. Terceiro, leva- nos a especular se a corrupção pode ser atribuída a fatores sociais, econômicos e políticos identificáveis, que podem ou não ser independentes da cultura, ou se a cultura interage com essas variáveis estruturais de uma maneira previsível. Por exemplo, alguns pesquisadores têm relacionado a corrupção com variáveis tais como o desenvolvimento econômico, a distribuição de renda, a estrutura governamental (TREISMAN, 1999), a "qualidade institucional" e outras variáveis econômicas e políticas. Merece a cultura política um lugar ao lado das demais variáveis ou será que a corrupção é simplesmente o reflexo do ambiente político e econômico prevalente?

A presente análise é um estudo preliminar da relação entre a corrupção e a cultura política. Esta análise tornou-se possível graças à inovação de índices internacionais e de classificações de corrupção, bem como pela crescente disponibilidade de indicadores culturais sofisticados gerados por pesquisas internacionais de opinião pública. Especificamente, pretendemos reunir dois grandes bancos de dados internacionais - o Corruption Perceptions Index e os World Values Surveys - com o objetivo de investigar a força das relações entre a corrupção e a cultura. Faremos isso controlando alguns fatores econômicos e políticos que podem explicar a variação internacional na corrupção, um método que nos permite isolar o impacto da cultura. Essa é essencialmente uma operação de mapeamento, que nos ajudará a gerar algumas conclusões preliminares e, desse modo, avaliar a plausibilidade das abordagens culturalistas da corrupção e refletir, por extensão, sobre temas mais profundos de democracia e de desenvolvimento.

A discussão que segue está dividida em quatro seções. Na primeira, examinaremos algumas das hipóteses existentes ligadas à corrupção e às suas relações com a cultura política. Na segunda, descreveremos e operacionalizaremos nossas variáveis e, na terceira seção, empregaremos essas variáveis em uma série de modelos multivariados simples, estimando o efeito da cultura sobre os níveis de corrupção percebidos. Isso nos permitirá gerar algumas proposições provocativas, ainda que preliminares, sobre os potenciais determinantes culturais da corrupção. Na seção final deste artigo abordaremos as dimensões teóricas e comparadas dos nossos resultados.

\section{FONTES POTENCIAIS DE CORRUPÇÃO: HIPÓTESES E RESULTADOS ANTERIORES}

Nesta seção examinaremos hipóteses apresentadas na literatura anterior sobre o tema da corrupção. Primeiramente discutiremos a cultura política, adotando uma abordagem ampla do conceito. Em seguida, investigaremos os fatores estruturais, como o regime político e o nível de desenvolvimento econômico.

\section{II.1. Determinantes culturais}

Na década passada, uma das mais influentes linhas de pesquisa sobre cultura política referiase à "confiança", tanto definida como confiança nas instituições (também conhecida como "political support" (NORRIS, 1999)), como confiança social (também conhecida como confiança interpessoal (INGLEHART, 2000a)). A confiança é um elemento crucial do conceito mais amplo de "capital social", ou seja, as normas, redes e outras formas de "conectarmo-nos" que permitem às pessoas trabalhar em conjunto mais efetivamente (PUTNAM, 1993; 2000; FUKUYAMA, 1995). Ao estudar a corrupção, 
pesquisadores têm abordado o conceito de confiança em todas as suas dimensões. Por exemplo, La Porta et alii (1997) defendem que a confiança ou capital social é responsável pelo desempenho superior de todas as instituições políticas e empresas privadas. Esses autores demonstram que quando os cidadãos não confiam no Estado para resolver disputas com justiça e eficiência, buscam alternativas como o pagamento de suborno e outros comportamentos corruptos. Dessa forma, concluem que a confiança pode ser útil na luta contra a corrupção, uma vez que ela ajuda os burocratas a cooperarem uns com os outros e com os cidadãos individualmente. De acordo com os autores, "a confiança promove a cooperação, especialmente no [...] desempenho governamental" (idem, p. 337; ver também PUTNAM, 1993; 2000; SELIGSON, 2002).

Husted (1999) também analisa a relação entre a confiança e a incidência de comportamento corrupto e chega a resultados similares. Ele argumenta que a confiança está inversamente relacionada à "incerteza", e que a incerteza, por sua vez, está positivamente relacionada à corrupção. "Em situações em que os resultados são incertos, a corrupção pode servir para assegurar um resultado mais preciso" (idem, p. 345). Isso reforça a observação de Newton (1999) de que "a confiança é o caminho para reduzir riscos e incerteza [...]. Sem confiança naqueles de quem dependemos, a vida diária seria sórdida, embrutecida e curta" (idem, p. 171). Na mesma linha dos argumentos apresentados por esses teóricos, a idéia de que a falta generalizada de confiança no governo gera corrupção, DellaPorta e Vanucci (1999) utilizam os resultados de um levantamento [survey] para demonstrar que a Itália, o país que possivelmente representa o caso de corrupção mais enraizada na Europa Ocidental, facilmente lidera as pesquisas de opinião comparada (Eurobarômetro) sobre os níveis de desconfiança no governo e de insatisfação com o sistema político, conduzidas periodicamente pela Comissão Européia.

Alguns estudiosos utilizam o termo "confiança" em um contexto diferente. As pessoas podem confiar umas nas outras por seus laços pessoais, que dependem do parentesco, ligações profissionais ou amizade. Esse tipo de confiança baseada nos laços pessoais e não na competência e legitimidade do Estado pode, na verdade, facilitar a transferência de recursos por meio de corrupção.
Em um ambiente corrupto, em que a lei não pode ser utilizada para fazer valer os contratos, "um funcionário público pode favorecer seus próprios parentes na alocação de concessões e de outros benefícios em troca de uma fatia desses benefícios" (ROSE-ACKERMAN, 1999, p. 98). Desse modo, a corrupção pode ser maior no nível local, devido à maior intimidade e frequiência de interações entre indivíduos e funcionários públicos. Há quatro décadas, o estudo clássico de Banfield (1958) já havia levantado a hipótese de uma conexão entre "familismo amoral" (favoritismo por membros da família) de uma pequena cidade no sul da Itália e a tendência dos funcionários públicos a aceitar propinas: "Em uma sociedade de familistas amorais, ninguém defenderá o interesse do grupo ou da comunidade exceto quando for de vantagem pessoal fazê-lo" (idem, p. 83-84; para um resumo, ver LIPSET \& LENZ, 2000, p. 120-121). Esses estudos sugerem que a corrupção pode nascer das normas sociais que enfatizam a lealdade à família ou ao clã em detrimento do Estado de Direito (ver também SCOTT, 1972; NEWTON, 1999).

Então, quando se discute a relação entre confiança interpessoal e corrupção política, é importante ser específico sobre a forma de "confiança" e a direção da relação esperada. Nossa abordagem concentra-se no efeito cimentador que a confiança interpessoal exerce nas instituições e no Estado de Direito - em outras palavras, nas possibilidades para normas auto-aplicáveis e para a dissuasão de comportamento corrupto. Como Larry Diamond (1999, p. 298) observa, "se a confiança é baixa e as expectativas dos cidadãos uns para com os outros são sistematicamente céticas, as instituições passam a ser meras formalidades, desprovidas de respeito e eficácia, uma vez que as pessoas abandonam a obediência na expectativa de que os demais farão o mesmo". Quanto maior o nível de confiança interpessoal em uma determinada sociedade, maior o compromisso com normas universalistas e com o Estado de Direito e menores as taxas esperadas de corrupção política.

Além da confiança, outra dimensão importante da pesquisa em cultura política diz respeito ao efeito independente de várias tradições religiosas sobre as atitudes e o comportamento humano. La Porta et alii (1997) estendem esse debate para a questão específica da corrupção. Os autores consideram a religião católica, a ortodoxa oriental 
e a muçulmana particularmente hierarquizadas. Eles defendem que essas formas hierarquizadas de religião são prejudiciais à participação cívica e facilitam o comportamento corrupto porque impedem a formação de "redes horizontais de cooperação entre as pessoas" (LA PORTA et alii, 1997, p. 337). Controlando a renda per capita, os autores descobriram que "países com religiões hierarquizadas mais dominantes apresentam judiciários menos eficientes, maiores níveis de corrupção, burocracias menos capacitadas e maiores índices de evasão fiscal" (idem, p. 336337).

Desse modo, onde as religiões mais hierarquizadas são dominantes, o questionamento das autoridades públicas tenderia a ser menos freqüente do que nas culturas caracterizadas por religiões mais igualitárias e individualistas, como o protestantismo. Mas há uma segunda razão para considerar a possibilidade que a religião possa afetar o nível de corrupção. De acordo com Treisman, em tradições religiosas como o protestantismo, que surgiram em algumas versões como seitas dissidentes em relação às religiões apoiadas pelo Estado, "instituições como a Igreja podem ter um papel de fiscalizar e denunciar funcionários públicos. Em outras tradições, como no Islã, onde as hierarquias da Igreja e do Estado estão intimamente interligadas, esse papel pode ficar ausente" (TREISMAN, 2000, p. 403). Huntington (1984) oferece um diagnóstico similar. De acordo com ele, as sociedades que são consummatory (fundamentalistas) por natureza, isto é, nas quais os fins intermediários e os objetivos finais estão intimamente ligados, são mais resistentes à mudança e constituem solo menos fértil para a confiança. Por exemplo, nos regimes islâmicos, não há distinção entre o Estado secular e religioso. Assim, o Estado impõe relações altamente hierarquizadas e valoriza a deferência extrema à autoridade. Por outro lado, culturas "instrumentais", em que se observa uma distinção entre fins intermediários e metas finais, caracterizam-se pela tolerância da diversidade e do conflito entre os membros da sociedade. Por conseguinte, as culturas protestantes, em que as orientações religiosas básicas nunca estiveram associadas a nenhuma estrutura política ou hierárquica em particular, têm-se mostrado mais hospitaleiras à democracia e à transparência.

Essas hipóteses provocativas têm inspirado pesquisas empíricas. Em uma análise quantitativa de 114 países, La Porta et alii (1999, p. 262) observam que "governos muçulmanos e católicos são menos eficientes, inclusive mais corruptos". No entanto, virtualmente todos esses efeitos tornam-se estatisticamente insignificantes uma vez que a variação da renda per capita é controlada. Os autores oferecem duas explicações plausíveis para o problema. Ou "os católicos e muçulmanos são menos produtivos, e isso se traduz em um governo inferior, ou o pior funcionamento dos governos dos países católicos reduz suas rendas, com o resultado de que o efeito negativo da filiação religiosa sobre a qualidade do governo é parcialmente capturado pela renda per capita" (idem, p. 262-263). Claramente, é difícil distinguir entre o impacto da economia e o da religião.

Por outro lado, alguns pesquisadores minimizam a importância da confiança e da religião e identificam outros fatores culturais que possam afetar a corrupção. Por exemplo, um estudo recente de Swamy et alii (1999) investiga o impacto do gênero sobre a corrupção ("gênero" sendo tratado aqui em sua dimensão sócio-cultural e não biológica). Numa análise estatística de 66 países, os autores determinam a porcentagem de mulheres na força de trabalho e no Parlamento, e descobrem que esses dois indicadores têm impacto negativo sobre o nível de corrupção. Além disso, a influência do gênero é altamente significativa e robusta em uma grande variedade de regressões, mesmo controlando diversas outras variáveis. Isso permite aos autores rejeitarem a idéia de que esses resultados intrigantes simplesmente refletem a renda per capita (uma vez que a participação feminina nos governos tende a ser maior nos países mais ricos). Para interpretar seus resultados, os autores sugerem a seguinte hipótese: se as sociedades discriminam as mulheres, apenas as mulheres excepcionalmente capazes e honestas (leia-se: menos tolerantes em relação à corrupção) podem tornar-se administradoras ou ministras de Estado. Assim, o diferencial de gênero verificado pelos autores pode derivar da diferença entre as mulheres excepcionais e os homens medianos (ibidem).

O impacto do gênero sobre a corrupção tem sido investigado sob diferentes ângulos. Discussões de gênero têm-se concentrado em diferenças importantes no conceito de "sucesso material" entre os sexos. Em um artigo recente, Husted (1999) argumenta que os dirigentes 
políticos em países onde as mulheres são comparativamente mais poderosas estariam mais dispostos a enfatizarem questões éticas nas práticas de negócios do que seus contrapartes em países com instituições políticas mais tradicionais, dominadas por homens. Isso porque os homens são "normalmente motivados pelo desejo de acúmulo pessoal de riquezas" (idem, p. 344). Uma maior tolerância na percepção de questões éticas nas práticas do governo e da iniciativa privada criariam assim mais espaço para que tais tomadores de decisão aceitassem práticas corruptas: "essa ênfase no sucesso material conduz a uma maior inclinação a participar em transações corruptas na busca desse mesmo sucesso material" (ibidem).

A conexão entre o nível de corrupção e determinantes culturais não deve sugerir que a cultura anula outros fatores explicativos. Como Inglehart demonstra persuasivamente em seus trabalhos recentes (INGLEHART, 1990; 1997), existem inter-relações complexas entre cultura e variáveis econômicas, políticas e institucionais. Por si mesma, a cultura pode, provavelmente, explicar apenas uma certa fração do nível de corrupção. Como Scott (1972, p. 3) aponta, "o padrão de corrupção de uma determinada nação em um determinado momento reflete a configuração das instituições políticas, dos valores populares e das clivagens sociais". Dessa forma, qualquer estudo sobre o efeito independente da cultura sobre a corrupção deve iniciar-se a partir de um projeto de pesquisa sensivelmente articulado, que incorpore numerosas variáveis de controle, de modo a evitar o determinismo cultural.

\section{II.2. Desenvolvimento econômico e democracia}

Diversos pesquisadores sugerem que os padrões de corrupção, ao invés de refletirem atributos culturais, são melhor atribuídos a fatores políticos e econômicos. Por exemplo, tanto economistas quanto cientistas políticos freqüentemente citam o nível de desenvolvimento econômico como uma variável explicativa importante. Jackman e Montinola (2002) verificam que a corrupção declina com o aumento do desenvolvimento econômico. Os autores atribuem esse declínio no comportamento corrupto a salários mais altos no setor público, que criam menos incentivos para o envolvimento em práticas corruptas (ver também HUSTED, 1999). Treisman (2000) argumenta que o desenvolvimento econômico também fomenta a alfabe- tização, a educação e a ampliação de relações nãopersonalizadas, todas aumentando as chances de que a corrupção governamental será reconhecida e enfrentada.

Cientistas políticos, em particular, concentramse no tipo de regime como um determinante importante do nível de corrupção. De acordo com esse argumento, os níveis de corrupção deveriam ser menores nos sistemas políticos mais democráticos e abertos, por diversas razões. A primeira é geralmente o mais alto nível de transparência propiciado pela poliarquia. Por exemplo, a liberdade de imprensa e de associação permite aos jornalistas e aos grupos de interesse exporem o comportamento corrupto. Uma segunda característica dos regimes democráticos é a competição. Nos sistemas democráticos, "candidatos aos cargos públicos têm um incentivo para descobrir e tornar público o abuso dos cargos por seus atuais detentores [incumbents] sempre que uma eleição surge no horizonte" (idem, p. 403). Uma terceira razão é o mais alto nível de accountability, notório nas democracias. Em um contexto de eleições livres e justas, os eleitores reservam-se o direito de "premiar" os ocupantes dos cargos - ao reelegê-los ou elevá-los a um posto mais alto - ou de "puni-los", ao destituí-los de seus postos. Nessas condições, pode-se esperar que os funcionários corruptos sejam "varridos" da vida pública - mas somente após serem flagrados em atividades corruptas. O fato de que a accountability democrático funcione post facto (combinada com a existência de uma imprensa livre e agressiva) ajuda a explicar por que podemos observar, esporadicamente, escândalos de corrupção tornados altamente públicos em democracias consolidadas, enquanto, ao mesmo tempo, notamos um nivel geral mais baixo de corrupção nesses sistemas.

Essas observações sugerem fortemente que qualquer exame do efeito da cultura sobre a corrupção deve controlar tanto o nível de desenvolvimento econômico quanto o grau de democracia política num determinado país. Tanto o desenvolvimento como a democracia têm sido medidos de várias formas na literatura existente. No nosso simples teste preliminar, conduzido abaixo, concentramo-nos apenas nas inter-relações hipotéticas entre desenvolvimento econômico, democracia, cultura e corrupção. Desagregamos o conceito de cultura, contextualizando-o para 
examinar como seus diversos componentes, acima discutidos, afetam o potencial para corrupção em uma base internacional.

\section{DADOS, VARIÁVEIS E FONTES}

Reunimos dados para uma amostra de até 79 países, incluindo tanto nações industriais avançadas como países menos desenvolvidos. Para medir a corrupção, utilizamos a edição 2000 do Corruption Perceptions Index (CPI) produzido pela Transparência Internacional (TI), uma organização não-governamental que monitora a corrupção no mundo. O CPI é uma "pesquisa de pesquisas" que mede a percepção do grau de corrupção em 90 países, aferido por empresários, analistas de risco e o público em geral (ver LAMBSDORFF, 2000a). A escala publicada do CPI varia entre 10 (altamente livre de corrupção) a 0 (altamente corrupto), mas aqui invertemos a pontuação de modo que os valores mais altos reflitam maiores níveis percebidos de corrupção. Como qualquer medida reputacional nas ciências sociais, o indicador de corrupção da TI tem pontos fortes (ver LAMBSDORFF, 2000b) e pontos fracos (ver JOHNSTON, 2000). No entanto, sua validade é bastante considerável, conforme veremos abaixo.

Em nossos esforços para avaliar o impacto da cultura sobre a corrupção, visamos a desenvolver medidas internacionais de tolerância social à corrupção. Para tanto, utilizamos os World Values Surveys (WVS), uma série de pesquisas de opinião conduzidas por uma equipe internacional de cientistas sociais, sob a direção de Ronald Inglehart. A primeira onda dos WVS foi conduzida entre 1981-1984, a segunda entre 1990-1993 e a terceira entre 1995-1997, todas com base em amostras nacionais probabilísticas de grande $N$ (INGLEHART, 2000b). Na terceira onda, os WVS foram expandidos para englobar 53 sociedades, que cobrem $70 \%$ da população mundial. Os WVS contêm questões sobre confiança interpessoal, percepções acerca da corrupção, tolerância a subornos e valores que facilitam um comportamento socialmente cooperativo ou "cívico".

$\mathrm{Na}$ tentativa de medir o comprometimento com o comportamento cívico, normas universalistas e o Estado de Direito, enfocamos uma bateria de questões que reúne os pontos de vista dos entrevistados sobre uma variedade de interações pessoais, tanto cotidianas como institucionais. Nos WVS de 1995-1997, a seguinte pergunta foi feita aos entrevistados: "Por favor, diga, para cada uma das seguintes afirmações, se você acredita que o cenário mencionado pode ser sempre justificado, nunca pode ser justificado, ou em alguma medida, usando esta escala". Na escala, o valor 1 representava o menos justificável enquanto o valor 10 o mais justificável. Os quatro cenários eram:

- requisitar benefícios do governo para os quais você não está habilitado;

- evitar a tarifa nos transportes públicos;

- sonegar impostos se você tiver a chance e

- comprar algo que você sabe que é roubado.

Utilizando as respostas a essas quatro questões, criamos um simples índice aditivo que varia de 4 a 40. Resultados que se aproximem do valor mínimo do índice (4) são regidos por orientações cívicas e de respeito à lei, e resultados que se aproximem do valor máximo do índice (40) são "não-cívicos" e avessos ao capital social, às normas universalistas e ao Estado de Direito. Norris (1999) empregou praticamente esse mesmo índice aditivo como medida de obediência à lei e descobriu que as variáveis componentes "agruparam-se [loaded] em uma única dimensão, o que proporcionava uma escala internamente consistente de obediência às leis" (idem, p. 264). Em seu modelo estatístico, a confiança no governo está positivamente associada à inclinação pessoal para respeitar a lei. De modo similar, Newton (1999) configura a mesma bateria de questões como um "índice de moralidade" e aponta uma trajetória significativa relacionando à moralidade em nível individual e à confiança interpessoal. Notamos também que o recente estudo de Putnam sobre os Estados Unidos utiliza survey questions equivalentes como indicadores de "capital social" (PUTNAM, 2000). Nossa hipótese é que cidadãos que apresentam orientações não-cívicas serão mais tolerantes às práticas corruptas no governo e na iniciativa privada. Essa expectativa segue a lógica de Banfield (1958), que argumentava que em sociedades não-cívicas "haverá pouca fiscalização dos funcionários, uma vez que a fiscalização dos funcionários é de responsabilidade de outros funcionários [corruptos]" (idem, p. 86; grifos no original).

Os WVS de 1995-1997 também perguntaram aos entrevistados se poderia ser justificado "alguém aceitar suborno no exercício de suas obrigações", utilizando a mesma escala de 1-10, como 
acima descrito. Essa é a melhor pergunta existente nas pesquisas sobre percepções globais de corrupção. Ainda que Norris (1999) tenha incluído essa questão (juntamente com as quatro perguntas anteriores acima reproduzidas) em seu índice de obediência às leis, nós tratamo-la separadamente aqui, não apenas porque introduz uma dimensão política que não está presente nas outras quatro perguntas, mas também porque é a pergunta mais diretamente pertinente para nossa variável de interesse, a corrupção. Tratamos as respostas a essa pergunta como uma medida robusta de tolerância social à corrupção política.

Os World Values Surveys são também a melhor fonte de dados existentes sobre níveis de confiança interpessoal no mundo. A questão-padrão dos WVS é: "De modo geral, você diria que se pode confiar na maioria das pessoas ou que se deve ser muito cuidadoso no relacionamento com as pessoas?" A porcentagem de pessoas que responderam "sim" constitui a nossa medida internacional de confiança social. Os países do mundo com mais alta confiança estão na Escandinávia; muitos dos países com menor confiança estão na América Latina. Utilizamos os dados da pesquisa mais recente disponível para cada país no levantamento, ou dados da segunda (1990-1993) ou terceira (1995-1997) ondas dos WVS. Obtivemos dados adicionais da América Latina utilizando os resultados da pesquisa do Latinobarómetro de 1996 conduzida por MORI International (LAGOS, 1997).

Outras variáveis independentes incluíram medidas de riqueza nacional, distribuição de renda, participação feminina no governo, religião, liberdade de imprensa e extensão dos direitos políticos e das liberdades civis. O impacto cultural das diferenças de gênero foi medido utilizando os dados da ONU (Organização das Nações Unidas) sobre a participação das mulheres em todos os níveis de governo. A distribuição das filiações religiosas foi estimada com base nos dados publicados pela Agência Central de Inteligência (CIA) dos EUA. A riqueza nacional foi medida utilizando dados da ONU sobre o Produto Interno Bruto (PIB) per capita real. Dados do Banco Mundial foram usados para medir as diferenças internacionais na distribuição de renda, utilizando o conhecido coeficiente de Gini de desigualdade.

Nossa variável para "liberdade da imprensa" foi retirada dos dados compilados pela Freedom
House para 186 países. O índice Freedom House pesquisa "leis e regulamentos que influenciam o conteúdo da imprensa", "a influência política sobre o conteúdo da mídia", "a influência econômica sobre o conteúdo da mídia" e "as ações repressivas" tomadas pelos governos nacionais. Invertemos o índice da Freedom House de modo que os valores variem de 0 (menor liberdade de imprensa) a 100 (maior liberdade de imprensa). As variáveis para liberdades civis e direitos políticos foram retiradas da pesquisa da Freedom House, Freedom in the World, uma avaliação anual dos direitos políticos e das liberdades civis em todo o mundo. A pesquisa atribui valores numa escala de sete categorias aos direitos políticos e às liberdades civis, em que o 1 representa o mais livre e o 7 o menos livre. Novamente, para facilitar a interpretação dos coeficientes em nossa análise, essas duas variáveis foram transformadas de modo que valores elevados representem maior liberdade. Nós seguimos métodos convencionais ao somar os valores para direitos políticos e civis, de modo a criar uma medida única para a democracia política, que varia de 2 (mais autoritário) a 14 (mais poliárquico).

\section{ANÁLISE DOS DADOS}

Nosso primeiro passo foi checar a validade de nossa variável dependente, o CPI divulgado pela Transparência Internacional. Obviamente, percepções sobre corrupção não são a mesma coisa que a corrupção. As percepções podem refletir impressões gerais de ineficiência ou de uma fraca sociedade civil, ou, até mesmo, de choque cultural, em vez de corrupção (JOHNSTON, 2000). Além disso, como assinala Johnston, escândalos aparentemente pequenos "podem ser carregados de significado invisível para osoutsiders [...] não familiarizados com as preocupações das elites" (idem, p. 18-19), enquanto outros casos de corrupção notados "podem ser na verdade escândalos estimulados por facções" (2000, p. 18). Um perigo adicional é que as percepções sobre corrupção podem levar a um problema de "câmara de eco", em que empresários, analistas de risco e investidores repetem o que ouvem uns dos outros, de modo que impressões superficiais, anedotas e boatos adquirem falsa autoridade por meio da repetição. Há um problema potencial de exogeneidade na medida de corrupção da TI. Em outras palavras, será que as percepções dos outsiders (ou seja, os avaliadores na "pesquisa das 
pesquisas" da TI) refletem com precisão o nível de corrupção de sociedades inteiras? Será que os investidores deixam de ver casos de corrupção ou, alternativamente, será que os empresários são menos honestos devido ao possível envolvimento de suas próprias empresas na prática de corrupção? No final das contas, até que ponto podemos confiar na honestidade dos relatos de visitantes?

Para enfrentar essas questões, examinamos a relação entre o índice da Transparência Internacional e as respostas à seguinte questão do World Values Survey de 1995-1997: "Até que ponto você acha que é comum, em seu país, a prática do suborno e a corrupção?" Os entrevistados receberam uma escala de 1 a 4 , em que o valor 1 significava que "quase nenhuma autoridade está envolvida", o 2 indicava "algumas poucas", o 3 "a maior parte" e o 4 significava que "quase todos" os membros do governo estavam envolvidos em corrupção. Essa pergunta do WVS foi feita em 36 países também cobertos pela base de dados da Transparência Internacional. A correlação entre "as percepções locais de corrupção" (geradas pelo WVS) e o Índice de Percepções sobre Corrupção (compilado de maneira independente pela TI) atingiu um grau impressionante $(r=0,87, p<0,001$, $N=36$ ). Esses resultados estimularam a confiança na medida CPI: em nível mundial, há um grau extraordinário de convergência nas percepções internas e externas de corrupção política (ver Gráfico 1). Dessa forma, ao ancorar o índice da TI em dados válidos, confiáveis e amplamente comparáveis do WVS, podemos confiar que o CPI não apresenta as excentricidades ou vieses de uma determinada organização de pesquisa, nem tampouco as especulações levianas dos assinantes da The Economist, mas sim que corresponde em alto grau à opinião do público nos países envolvidos.

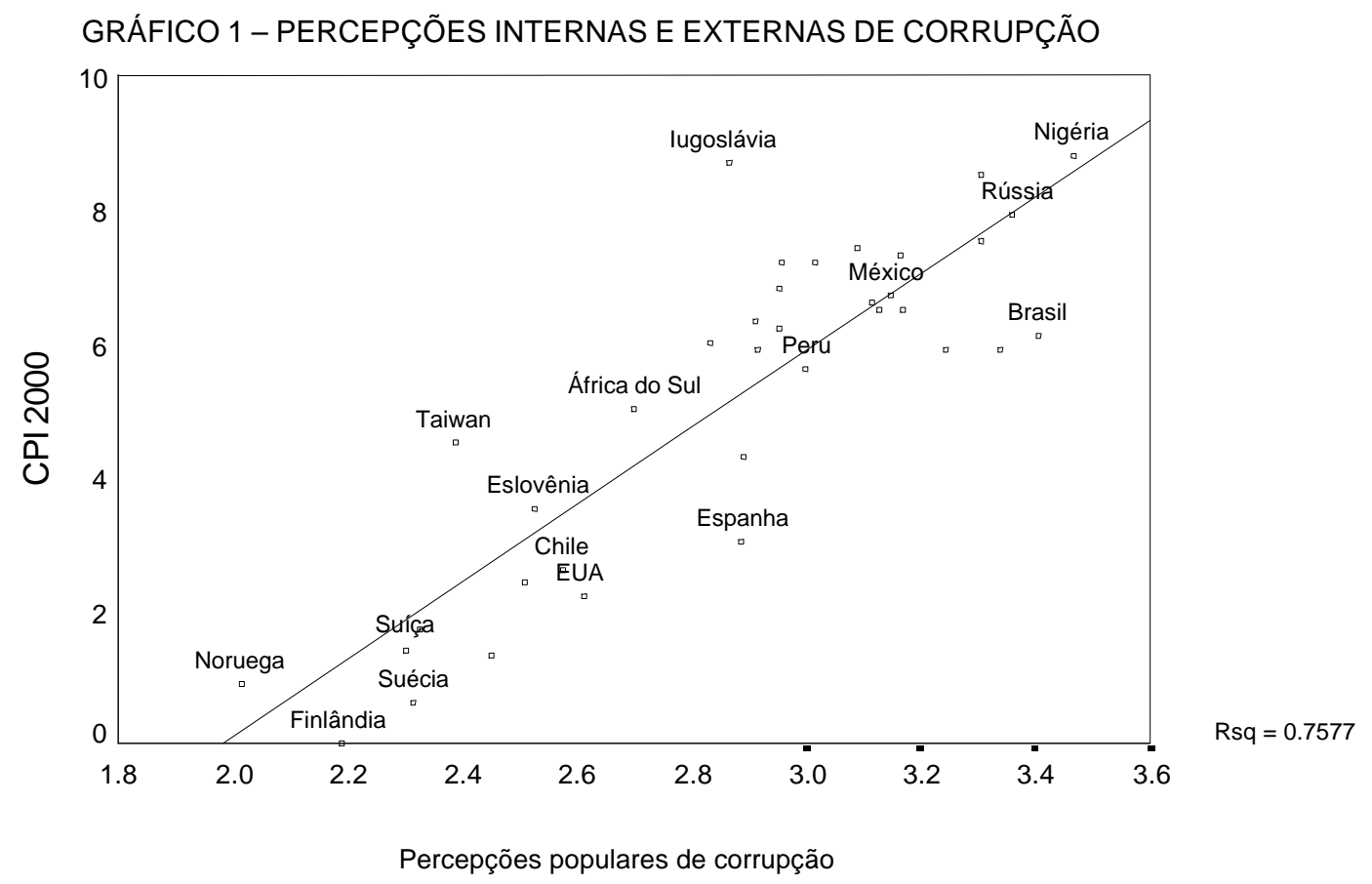

FONTES: Transparência Internacional (2000); Inglehart (2000b).

Nosso segundo passo foi realizar um exame preliminar de correlações bivariadas entre o CPI e nossa lista de variáveis independentes. Os coeficientes de correlação são apresentados na Tabela 1. Para nossas variáveis de controle, que medem as condições político-econômicas prevalecentes, todas as quatro variáveis apresentam a polaridade esperada e são estatisticamente significantes. A correlação mais forte verifica-se com a riqueza nacional. O PIB per capita apresenta uma correlação extraordinária de $-0,88$ com os níveis de corrupção percebidos tais como medido pelo CPI. A desigualdade de renda, em contraste, apresenta uma correlação muito mais fraca. Democracia política e liberdade de imprensa comportam-se da maneira prevista, 
também com fortes coeficientes de correlação. Esse primeiro corte gera os resultados esperados: a corrupção parece ser prevalente nas sociedades mais pobres e mais autoritárias.

TABELA 1 - CORRELAÇÕES SIMPLES COM O ÍNDICE DE PERCEPÇÕES DE CORRUPÇÃO (2000) DA TRANSPARÊNCIA INTERNACIONAL, EM NÍVEL MUNDIAL

\begin{tabular}{|l|r|r|r|}
\hline Variável (e relação esperada) & $r$ & Significância & N países \\
\hline Indicador alternativo de corrupção & & & \\
\hline $\begin{array}{l}\text { Percepção popular de corrupção } \\
\text { World Values Survey de 1995-1997 (+) }\end{array}$ & 0,87 & 0,000 & 36 \\
\hline Variáveis culturais & & & \\
\hline Confiança interpessoal (-) & $-0,64$ & 0,000 & 54 \\
\hline Orientações não-cívicas (+) & 0,30 & 0,035 & 50 \\
\hline Tolerância de suborno (+) & 0,39 & 0,004 & 53 \\
\hline Porcentagem protestante (-) & $-0,70$ & 0,000 & 37 \\
\hline Porcentagem católica (+) & $-0,07$ & $\mathrm{NS}$ & 45 \\
\hline Porcentagem islâmica (+) & 0,37 & 0,012 & 45 \\
\hline Mulheres em todos os níveis de governo (-) & $-0,48$ & 0,000 & 79 \\
\hline Condições econômicas e políticas & & & \\
\hline PIB per capita (-) & $-0,88$ & 0,000 & \\
\hline Desigualdade de renda (+) & 0,33 & 0,004 & \\
\hline Democracia política (-) & $-0,67$ & 0,000 & \\
\hline Liberdade de imprensa (-) & $-0,69$ & 0,000 & \\
\hline
\end{tabular}

FONTES: United Nations (1999); CIA (2000); Freedom House (2000); Inglehart (2000b); World Bank (2000).

As variáveis de cultura política também são significantes, com uma exceção: a porcentagem da população que é católica não está relacionada aos níveis de corrupção. O protestantismo e o islamismo, por outro lado, mostram as relações previstas com a corrupção, com o protestantismo apresentando a mais forte correlação bivariada entre todos os sete fatores culturais examinados. Tanto a tolerância ao suborno e o nível de orientações não-cívicas (ou de não-obediência à lei) demonstram relações moderadas e significativas com o CPI. Como antecipado por uma longa tradição de pesquisa no estudo comparado de cultura política, o nível de confiança interpessoal apresenta uma forte relação negativa com a corrupção (Gráfico 2). Finalmente, a presença de mulheres no governo, como previsto em estudos anteriores, também está relacionada negativamente ao CPI. A simples análise bivariada indica que há uma sólida base para nossa investigação acerca da relação entre cultura e corrupção. 
GRÁFICO 2 - CORRUPÇÃO E CONFIANÇA INTERPESSOAL

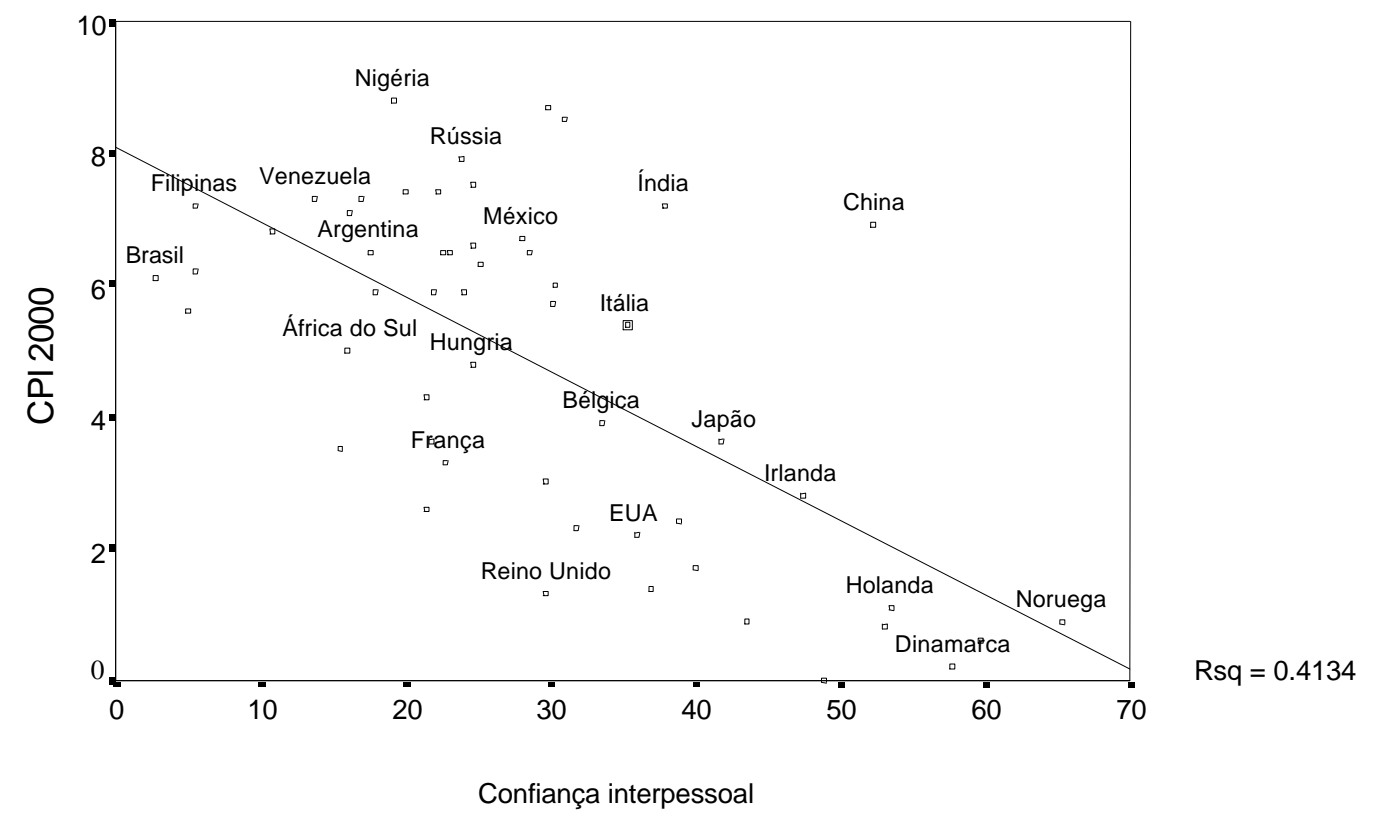

FONTES: Inglehart (2000b); Transparência Internacional (2000).

Nosso terceiro passo foi realizar análises multivariadas em que examinamos os efeitos da cultura sobre a corrupção enquanto controlamos as condições estruturais, nesse caso o ambiente político-econômico. As análises multivariadas apresentam diversos problemas, todos eles comuns a pesquisas do tipo cross-national. Em primeiro lugar, confrontamo-nos com a falta de dados para diversas variáveis independentes, sendo que os indicadores sobre a filiação religiosa eram os menos completos. Seguindo o procedimento padrão de exclusão listwise dos casos não disponíveis, o $N$ disponível foi reduzido para os modelos de regressão a quadrados mínimos (OLS). Um segundo problema foi que o número pequeno de casos combinado com a relativamente grande lista de variáveis independentes causou volatilidade nos modelos. Tendo em vista esses obstáculos, tentamos maximizar nossa margem estatística ao abandonar algumas variáveis independentes - assim eliminando, sempre que possível, a duplicação teórica. Optamos por estimar modelos minimalistas mais adequados ao tamanho reduzido da amostra.

Em nossos esforços para examinar o efeito das variáveis culturais enquanto controladas as condições político-econômicas, enfrentamos escolhas difíceis ao reduzir a lista de variáveis. Dado que o nível de liberdade da imprensa está demasiadamente correlacionado com o nível de democracia política $(r=0,94, N=95)$, mantivemos os valores para a democracia da Freedom House e deixamos a variável sobre a imprensa fora de nossa análise. De maneira similar, em nosso esforço para encontrar uma única variável representativa (proxy variable) para as condições econômicas, descobrimos que a variável "PIB per capita" dominava a variável "desigualdade de renda" de modo consistente em todas as estimativas e, por isso, deixamos o coeficiente de Gini fora dos modelos. Ficamos com proxies simples para democracia e desenvolvimento: os valores da Freedom House e o PIB per capita. Ainda que, em termos de especificação de modelo, essa seja uma solução menos satisfatória, optamos pela estratégia comum de trocar complexidade teórica inatingível por vantagem estatística alcançável. Os cortes resolveram o problema de termos modelos OLS altamente "sobrecarregados", e ao mesmo tempo permitiram-nos manter algumas variáveis essenciais de controle, assim possibilitando nossa análise exploratória. (Não eliminamos, no entanto, potenciais sobreposições similares entre nossas variáveis de cultura política - por exemplo, confiança interpessoal, orientações não-cívicas e tolerância ao suborno - porque um de nossos objetivos é precisamente determinar quais deles têm o maior poder explicativo independente.) Procedemos, então, à estimativa 
de modelos que isolem os efeitos dos atributos culturais sobre os níveis de corrupção percebidos.

Esses modelos simples (modelos 1 a 7) estão apresentados na Tabela 2 . A variável dependente é o CPI. Os modelos 1 a 3 examinam três variáveis independentes derivadas do WVS, com o número de casos (países) variando de 46 a 48. Em cada um dos três modelos as variáveis de controle para democracia e desenvolvimento permanecem altamente significativas e na direção prevista, e cada modelo explica aproximadamente $80 \%$ na variância no CPI. A variável cultural que apresenta o melhor desempenho é a de confiança interpessoal (Modelo 1). A confiança tem um efeito negativo e altamente significativo sobre a variável dependente mesmo quando controlamos o PIB per capita e as liberdades políticas. Essa descoberta é intrigante porque sugere que, contrariamente às interpretações fáceis, a confiança mútua entre os membros de uma dada sociedade não é simplesmente um resultado do ambiente econômico (pobreza ou riqueza) ou do regime político (ditadura ou democracia). $\mathrm{Na}$ verdade, conforme sugerido por Banfield, o nível de confiança social revela-se como uma dimensão singular dentro da qual há diferenças importantes entre as nações - ricas e pobres, livres e nãolivres - em termos de seus níveis percebidos de corrupção. Note-se que, em termos de significância estatística, a variável confiança apresenta desempenho ainda melhor que a variável tolerância a suborno (Modelo 3), sendo esta a que imaginávamos oferecer a maneira mais direta para medir a inclinação sócio-cultural para práticas corruptas. A variável final derivada do WVS, “orientações não-cívicas" (basicamente o inverso do morality index de Newton), acabou não apresentando nenhum efeito estatisticamente significante sobre corrupção quando o PIB e a democracia estão controlados (Modelo 2). Acima de tudo, dentro da família de medidas geradas pelo WVS, a confiança interpessoal domina as outras características culturais.

TABELA 2 - EFEITOS SEPARADOS DE VARIÁVEIS CULTURAIS SOBRE O ÍNDICE DE PERCEPÇÕES DE CORRUPÇÃO, CONTROLANDO DEMOCRACIA E DESENVOLVIMENTO

\begin{tabular}{|c|c|c|c|c|c|c|c|c|c|c|c|c|c|c|}
\hline Modelo & & 1 & & 2 & & 3 & & 4 & & 5 & & 6 & & 7 \\
\hline Variável & $b$ & $t$ & $b$ & $t$ & $b$ & $t$ & $\mathrm{~b}$ & $\mathrm{t}$ & b & $t$ & b & $t$ & $b$ & $\mathrm{t}$ \\
\hline $\begin{array}{l}\text { Confiança } \\
\text { interpessoal }\end{array}$ & $-0,030$ & $-2,124^{\star \star \star}$ & & & & & & & & & & & & \\
\hline $\begin{array}{l}\text { Tolerância de } \\
\text { suborno }\end{array}$ & & & & & 0,537 & $1,672^{*}$ & & & & & & & & \\
\hline \% Islâmico & & & & & & & & & & & $-0,005$ & $-1,066$ & & \\
\hline $\begin{array}{l}\text { Mulheres no } \\
\text { governo }\end{array}$ & & & & & & & & & & & & & $-0,051$ & $-2,612^{\star \star \star}$ \\
\hline PIB per capita & $-1,927$ & $-6,465^{\star \star \star}$ & $-2,206$ & $-7,419^{\star \star \star}$ & $-2,047$ & $-7,221^{\star \star \star}$ & $-1,809$ & $-5,726^{\star \star \star}$ & $-1,821$ & $-6,758^{\star \star \star}$ & $-2,170$ & $-8,097^{\star \star \star}$ & $-2,140$ & $-11,621^{\star \star \star}$ \\
\hline Democracia & $-0,153$ & $-1,933^{\star \star}$ & $-0,179$ & $-2,110^{\star \star}$ & $-0,178$ & $-2,206^{\star \star \star}$ & $-0,238$ & $-2,660^{\star \star \star}$ & $-0,268$ & $-2,844^{\star \star \star}$ & $-0,150$ & $-2,122^{\star \star}$ & $-0,067$ & $-1,303$ \\
\hline
\end{tabular}

FONTE: United Nations (1999); CIA (2000); Freedom House (2000); Inglehart (2000b); World Bank (2000).

NOTA: Níveis de significância: ${ }^{*} p<0,10 ;{ }^{* *} p<0,05 ;{ }^{* * *} p<0,01$.

Os modelos 4 e 6 apresentam os efeitos independentes da tradição religiosa. (Comparado a modelos anteriores, o número de casos é ligeiramente menor aqui devido aos dados não disponíveis sobre filiação religiosa.) Vale ressaltar que, no nível bivariado, verificamos que o CPI correlacionava-se negativamente com o protestantismo, positivamente com o islamismo, e não havia qualquer relação com o catolicismo. Os resultados são intrigantes: quando controlamos a democracia e o desenvolvimento, apenas a variável protestantismo permanece estatisticamente significante. Isso sugere duas observações importantes: primeiramente, a variável protestantismo não é apenas uma proxy para países ricos ou democráticos, sugerindo que há de fato 
algo singular em torno dessa tradição religiosa e que podemos estar deparando-nos com um impacto cultural duradouro oriundo da Reforma. Em segundo lugar, qualquer correlação aparente entre corrupção e o islamismo é espúria. A corrupção no mundo islâmico provavelmente constitui um reflexo da pobreza, do autoritarismo ou da combinação desses dois fatores.

O Modelo 7 isola o efeito da participação feminina no governo sobre o nível percebido de corrupção. Assim como esperado, essa variável tem um efeito negativo no CPI. Nesse modelo, o controle da variável PIB per capita tem um efeito poderoso, mas os valores democráticos da Freedom House perdem sua significância estatística. Ainda que esse modelos sejam puramente exploratórios e simplificados, o Modelo 7 sugere que quando mantemos a riqueza nacional constante, a feminização da classe política pode, de fato, ter um efeito dissuasivo sobre a corrupção, um efeito que é mais decisivo que até o próprio nível de poliarquia. À primeira vista, isso parece sublinhar os resultados mais fortes sobre "gênero versus corrupção" obtidas por Swamy et alii (1999).

Os modelos 1 a 7, desse modo, sugerem que a confiança interpessoal, a porcentagem de protestantes na população do país e a porcentagem de mulheres na política têm todos um efeito potencial importante sobre o CPI. O próximo passo em nossa análise foi o de utilizar essas três variáveis independentes promissoras em uma série de modelos multivariados, em que cada estimativa mantém nossos controles para a democracia e o desenvolvimento. Essas regressões, utilizando as três variáveis independentes em todas as possíveis combinações, são apresentadas nos modelos 8 a 11 na Tabela 3.

TABELA 3 - MODELOS MULTIVARIADOS DO EFEITO DA CULTURA SOBRE A CORRUPÇÃO

\begin{tabular}{|c|c|c|c|c|c|c|c|c|c|c|}
\hline Modelo & \multicolumn{2}{|c|}{8} & \multicolumn{2}{|c|}{9} & \multicolumn{2}{|r|}{10} & \multicolumn{2}{|c|}{11} & \multicolumn{2}{|r|}{12} \\
\hline Variável & $\mathrm{b}$ & $\mathrm{t}$ & $\mathrm{b}$ & $\mathrm{t}$ & $b$ & $\mathrm{t}$ & $\mathrm{b}$ & $\mathrm{t}$ & $\mathrm{b}$ & $\mathrm{t}$ \\
\hline $\begin{array}{l}\text { Confiança } \\
\text { interpessoal }\end{array}$ & $-0,040$ & $-1,702^{*}$ & $-0,040$ & $-1,729^{*}$ & & & $-0,029$ & $-2,102^{* \star}$ & & \\
\hline \multicolumn{11}{|l|}{$\begin{array}{l}\text { Orientações } \\
\text { não-cívicas }\end{array}$} \\
\hline \multicolumn{11}{|l|}{$\begin{array}{l}\text { Tolerância de } \\
\text { suborno }\end{array}$} \\
\hline$\%$ Protestante & $-0,013$ & $-1,252$ & $-0,012$ & $-1,259$ & $-0,023$ & $-3,562^{\star \star \star *}$ & & & & \\
\hline \multicolumn{11}{|l|}{ \% Católico } \\
\hline \multicolumn{11}{|l|}{ \% Islâmico } \\
\hline $\begin{array}{l}\text { Mulheres no } \\
\text { governo }\end{array}$ & 0,006 & 0,240 & & & $-0,015$ & $-0,664$ & $-0,044$ & $-1,847^{\star}$ & & \\
\hline PIB per capita & $-1,740$ & $-4,085^{\star \star \star}$ & $-1,734$ & $-4,178^{\star \star \star}$ & $-1,813$ & $-5,685^{\star \star \star}$ & $-1,841$ & $-6,257^{\star \star \star}$ & $-2,190$ & $-11,524^{\star \star \star}$ \\
\hline Democracia & $-0,138$ & $-0,197$ & $-0,137$ & $-0,935$ & $-0,219$ & $-2,305^{\star *}$ & $-0,133$ & $-1,715^{\star}$ & $-0,112$ & $-2,252^{* \star}$ \\
\hline Constante & 9,614 & $6,639^{\star \star \star}$ & 9,659 & $6,892^{\star \star \star}$ & 9,951 & $12,220^{\star * *}$ & 9,706 & $12,357^{\star \star \star *}$ & 8,386 & $18,994^{\star * *}$ \\
\hline R2 ajustado & 0,88 & & 0,88 & & 0,89 & & 0,81 & & 0,78 & \\
\hline$N$ & 25 & & 25 & & 34 & & 50 & & 79 & \\
\hline
\end{tabular}

FONTE: United Nations (1999); CIA (2000); Freedom House (2000); Inglehart (2000b); World Bank (2000).

NOTA: Níveis de significância: * $p<0,10,{ }^{* *} p<0,05{ }^{* * *} p<0,01$

O Modelo 8 combina as variáveis "confiança social", "protestantismo" e "mulheres no governo" para estimar a corrupção, adotando os controlespadrão. O Modelo 9 retira a variável "mulheres no governo". Ainda que o número de casos seja reduzido substancialmente nesses modelos (apenas 25 países), eles apontam para o efeito dominante da variável confiança interpessoal vis-à-vis outras variáveis independentes. As variáveis "democracia" e "protestantismo" tornam-se insignificantes nos dois modelos, da mesma forma que a variável mulheres no poder, com o sinal tornando-se positivo nessa variável no Modelo 8. No Modelo 9, os controles para as variáveis "protestantismo", 
"PIB" e "democracia" tendem a capturar características de muitos países ricos do Atlântico Norte - e vimos aqui que a variável "mulheres no governo" perde significância quando controlamos esses três fatores comuns às democracias industriais avançadas. Utilizando apenas as variáveis "protestantismo" e "mulheres no poder" juntas para estimar o nível de corrupção (Modelo 10), novamente verificamos que o protestantismo tem influência primordial no modelo. O Modelo 11, utilizando as variáveis "confiança" e "mulheres no poder", novamente mostra a relação aparentemente forte e consistente entre a corrupção e a confiança interpessoal, tal como fortemente sugerido pelo Gráfico 2.

O Modelo 12 é apresentado como um contraste para as análises anteriores, ou seja, um tipo de "referência" contra o qual as outras estimativas podem ser avaliadas. É um modelo de duas variáveis simples em que apenas nossas duas principais variáveis de controle, "PIB per capita" e "nível de democracia", são usadas para prever o CPI. Esse modelo revela que, para uma amostra de 79 países, se soubéssemos apenas o nível de riqueza nacional e democracia nas nações, isso nos permitiria prever $78 \%$ da variância internacional no Índice de Percepções de Corrupção. O conjunto dos 12 modelos, com as simples correlações bivariadas apresentadas na Tabela 1, sugerem que a renda per capita média é o mais dominante dos dois fatores.

Os resultados da análise multivariada, dessa forma, geram quatro observações principais. Em primeiro lugar, a confiança interpessoal, componente essencial da teoria do capital social de Robert Putnam, tem um efeito negativo, robusto e consistente sobre a corrupção. Em segundo lugar, uma tradição religiosa protestante parece menos importante que um elevado nível de confiança social para conter a corrupção. Terceiro, estimativas multivariadas parecem enfraquecer de alguma forma a proposição derivada de Swamy et alii (1999) de que o poder político feminino tem um efeito negativo forte e independente sobre a corrupção - mas lembramos que o pequeno número de casos nos modelos 8 a 10 dá-nos menos margem estatística do que em equações alternativas. No entanto, o maior número de casos no Modelo $7(N=79)$ constitui um forte apelo para continuar a trabalhar na hipótese do gênero. Em quarto lugar e finalmente, deveríamos ressaltar o efeito impressionante das variáveis
"PIB" e "democracia" em todos esses modelos. Apenas conhecendo o nível comparativo de democracia e desenvolvimento de um país já é possível prever uma grande quantidade de variância nos níveis percebidos de corrupção - e dado que aproximadamente quatro quintos da variância em corrupção pode ser explicada dessa forma, torna-se claro que incorporar variáveis culturais à análise trará apenas vantagens limitadas em termos de robustez estatística.

\section{DISCUSSÕES E CONCLUSÕES}

Ao discutir nossos resultados, é importante enfatizar as limitações da abordagem aqui utilizada. Em primeiro lugar, o Índice de Percepções de Corrupção produzido pela Transparência Internacional está apropriadamente denominado: é uma medida reputacional, não um indicador empírico de casos concretos de corrupção. Claramente, um indicador mais empiricamente embasado acerca da extensão e intensidade da prática de corrupção seria preferível ao CPI, mas essa futura medida empírica provavelmente continuará a vexar os pesquisadores por muito tempo, senão para sempre (devido à natureza do fenômeno). Além disso, a amplitude e cobertura tanto da classificação TI de corrupção e do World Surveys Values, mesmo que grandemente aumentadas nos últimos anos, ainda nos limita a aproximadamente 50 casos cobertos pelas duas bases de dados - apenas um quarto das nações independentes do mundo. Um problema adicional é que os dados não disponíveis para algumas de nossas variáveis independentes reduziram nossa margem estatística ainda mais. Finalmente, devido aos fatores anteriormente mencionados, fomos obrigados a especificar modelos mínimos da relação entre a cultura política e a corrupção, com apenas os mais básicos controles para fatores político-econômicos. Seria preferível reduzir o erro de especificação por meio da inclusão em nossos modelos de variáveis mais precisas - por exemplo, aspectos mais finos das instituições políticas e das estruturas econômicas, ou da capacidade do Estado, fatores que presumivelmente influem na probabilidade de corrupção. No futuro, à medida que nossos esforços para coletar dados internacionais avançam, tornar-se-á indubitavelmente possível incorporar tais variáveis ao lado dos fatores culturais.

A despeito dessas limitações, nosso esforço de 
combinar as bases de dados do CPI e da WVS em uma única análise representa um avanço em relação a pesquisas anteriores e permite-nos, ao menos preliminarmente, encarar a relação entre cultura e corrupção. Tendo em conta os resultados gerais de nosso mapeamento, estudiosos podem legitimamente discordar se a cultura política teria um papel predominante em estudos comparados sobre corrupção. De um lado, o impacto da cultura é perceptível e real. Fatores como a confiança social e a tradição religiosa parecem influir na propensão de um país para a corrupção, ao menos tal como ela é estimada pelo CPI. Por outro lado, quando enxergamos a totalidade de fatores que possam afetar o ambiente para a corrupção, as diferenças culturais podem ter, na melhor das hipóteses, um impacto apenas moderado. Isso quer dizer que a cultura "importa" mas, quando comparada a fatores tais como a riqueza nacional e a democracia política, ela pode não "importar muito". Analisando os países em desenvolvimento em especial, os detratores de abordagens culturalistas podem fazer a seguinte pergunta: tendo em vista os imensos obstáculos para assegurar o Estado de Direito e a probidade administrativa nos países pobres e/ou sistemas políticos fechados, que porcentagem da probabilidade de sucesso pode ser realmente atribuída a traços culturais? Em síntese, enquanto defensores do culturalismo enxergariam "provas" em nossos resultados - a cultura está sem dúvida presente na equação - os anticulturalistas adotariam uma postura muito mais cética, destacando a importância de fatores macro e microeconômicos na determinação da possibilidade de corrupção.

Esse debate pode tomar ainda um outro rumo quando se olha para as últimas quatro décadas de pesquisa comparada em cultura política. Há muito nessa literatura que sugere que os fatores culturais podem já ter sido capturados pelas diferenças internacionais contemporâneas na democracia e na riqueza nacional: em outras palavras, que as "variáveis de controle" em nossos modelos já podem ter absorvido alguns dos efeitos da variável independente primária, a cultura. As estruturas político-econômicas contemporâneas podem constituir os efeitos tardios [lagged effects] de mudanças culturais anteriores, tal como Weber (1958) sugeriu quase um século atrás em seu famoso ensaio $A$ ética protestante e o espírito do capitalismo. Weber citou a ascensão da teologia calvinista, com sua ênfase no individualismo e na predestinação, como um fator primordial na explicação de porquê as áreas protestantes do Norte da Europa foram as primeiras a industrializarem-se. Modificando esse argumento para a segunda metade do século XX, Ronald Inglehart $(1977 ; 1988 ; 1990 ; 1997)$ desenvolveu a teoria do "pós-materialismo" para explicar porque algumas dessas mesmas áreas do Norte da Europa (hoje os países mais avançados social e economicamente do mundo) apresentam algumas das mais baixas taxas de crescimento do mundo nos dias de hoje. Essa linha de raciocínio defende que mudanças culturais geram mudanças políticoeconômicas, que logo estimulam uma nova rodada de adaptações culturais a essas mesmas mudanças, e que estas, por sua vez, novamente modificam as estruturas político-econômicas e assim por diante, ao longo da história. Dessa forma, existe a possibilidade de que nas democracias industriais avançadas fatores culturais tenham operado como um pano de fundo histórico para gerar os elevados níveis de democracia e desenvolvimento atuais e que, de alguma maneira, esses fatores históricos e culturais também operaram no sentido de conter a corrupção política nessas mesmas sociedades.

Tomemos, por exemplo, a aparente relação entre a democracia e um de nossos fatores culturais centrais, a confiança interpessoal. Desde os trabalhos clássicos da escola da modernização (ALMOND \& VERBA, 1963; INKELES \& SMITH, 1974) até hoje, os teóricos culturalistas argumentam que a confiança interpessoal está causalmente ligada à sustentabilidade da democracia. Em seu estudo pioneiro de cinco países, The Civic Culture, Almond e Verba observaram a aparente correlação entre confiança social e confiança nas instituições democráticas e lançaram a hipótese de que um "público confiante" [trusting public] era um aspecto-chave da legitimidade do regime. Mais recentemente, pesquisas comparadas em nível mundial detectaram uma forte relação empírica entre confiança interpessoal e o número de anos ininterruptos de democracia em um país. Por exemplo, para as 43 sociedades analisadas no WVS de 1990-1993, a correlação entre o número de anos consecutivos de democracia e a porcentagem de cidadãos dizendo que "se pode confiar na maioria das pessoas" era um forte $0,72(N=43$, $p<0,0001$ ) (INGLEHART, 1997, p. 174). A confiança e a estabilidade democrática, ao que 
parece, andam de mãos dadas.

Essa correlação, no entanto, remonta a uma pergunta do tipo "quem nasceu primeiro, o ovo ou a galinha?": é a democracia estável que gera a confiança social, ou será que a confiança social é que produz instituições democráticas? (Acreditamos que essa pergunta também é pertinente com relação à corrupção.) Todas as três respostas possíveis estão presentes na literatura. Muller e Seligson (1994), em um estudo de 27 países europeus e centro-americanos, defendem que a experiência democrática causa a confiança interpessoal. Putnam (1993), em sua comparação histórica entre o Norte e o Sul da Itália, sugerem que a confiança fortalece as instituições democráticas. Inglehart, ao contrário, é muito cauteloso em não especificar a direção da causalidade, preferindo enfatizar a existência de uma "afinidade eletiva" entre a confiança e a democracia: "As evidências disponíveis não podem determinar a direção da relação causal, mas indicam que a cultura e as instituições políticas têm uma forte tendência a caminharem juntas - sendo a confiança e a democracia estável intimamente ligadas, tal como a literatura em cultura política defende há muito tempo" (INGLEHART, 1997, p. 174). É possível defender a mesma causalidade recíproca com respeito à relação entre a confiança interpessoal e a corrupção (ou a falta de corrupção).

Inglehart está correto no que se refere ao fato de que os dados disponíveis, combinados com a imperfeição de metodologias comparadas que visam a englobar muitas sociedades, tornam difícil esclarecer as inter-relações entre confiança, democracia, riqueza nacional e corrupção. No entanto, há boas razões para acreditar que esses quatro fatores formam uma síndrome previsível, com altos níveis dos primeiros três fatores causando mais baixos níveis de corrupção. Observamos que a confiança interpessoal é necessária para realizar a alternância nas elites governantes que é uma característica fundamental das democracias estáveis. De modo simples mas brilhante, Przeworski definiu a democracia como "um sistema em que partidos perdem eleições" (PRZEWORSKI, 1991, p. 10). Inglehart complementa que "as instituições democráticas dependem da confiança em que a oposição aceitará as regras do processo democrático. Deve-se encarar os opositores políticos como uma oposição leal que não o prenderá ou aniquilará se você entregar o poder a ela, mas em que se pode confiar que vai governar dentro da lei e que abrirá mão do poder se perder as próximas eleições" (INGLEHART, 1997, p. 172). De maneira similar, Diamond defende que "a confiança está fundamentada na cooperação. Se as elites políticas rivais não confiam umas nas outras para honrar acordos, será muito mais difícil para elas institucionalizarem os pactos, compromissos, entendimentos e restrições mútuas que estabilizam o jogo político e consolidam a democracia no nível das elites" (DIAMOND, 1999, p. 160-161). Nesses argumentos sobre a "alternância no poder", a confiança opera como um tipo de "filtro" que determina até que ponto as regras do jogo democrático serão respeitadas.

A confiança, nessa visão, está causalmente ligada à democracia sustentável, e sabemos que a democracia, por sua vez, está associada a níveis mais baixos de corrupção política. No entanto, como verificamos em nossa análise empírica, existe um retorno adicional da confiança social: mesmo quando controlando o nível de democracia, taxas elevadas de confiança interpessoal resultam em níveis menores de percepções da corrupção. Não está claro, no entanto, o que está acontecendo no interior dessa caixa preta: nossa análise simples não pode nos dizer se (1) a confiança social é alta porque a corrupção é baixa, ou (2) a corrupção é baixa porque a confiança interpessoal é alta. Observamos que essa última premissa orienta a teoria de capital social inovada por Robert Putnam (1993; 2000). Segundo o autor, "a teoria do capital social presume que, de modo geral, quanto mais relacionamo-nos com outras pessoas, mais confiamos nelas, e vice-versa" (PUTNAM, 1995b, p. 665). No modelo de Putnam, a confiança interpessoal está associada à tendência de proliferação de associações secundárias e com o resultante crescimento no poder da sociedade civil. À medida que o associativismo em uma determinada sociedade cresce, formas "privadas" de interação política, como o clientelismo e a corrupção, desgastam-se; estilos "públicos" ou "cívicos" de política, baseados em noções republicanas de cidadania, enraízam-se mais e, talvez mais importante, os cidadãos obtêm mais poder [empowered], permitindo que possam manter seus líderes políticos mais responsáveis ou accountable (PUTNAM, 1993, p. 86-91; ver também PUTNAM, 1995a; 1995b). A 
accountability é o inimigo número um da corrupção. Baseado no extenso trabalho de Putnam sobre a Itália e os Estados Unidos, torna-se claro que a confiança interpessoal, o engajamento cívico e a democracia efetiva são fortemente intercorrelacionados e que todos os três têm presumivelmente um efeito dissuasivo sobre a corrupção.

Se os níveis contemporâneos de democracia incorporam os lagged effects da cultura, é razoável supor que o mesmo é verdade para os níveis contemporâneos de desenvolvimento econômico. Novamente, citamos uma longa tradição de trabalhos empíricos e teóricos, de Weber a Inglehart, que sugerem que as variáveis culturais exercem um forte impacto na propensão de uma dada sociedade para o crescimento econômico. Por motivos que têm mais a ver com os meandros da academia que com a plausibilidade empírica dessas teorias, as abordagens culturalistas sobre o desenvolvimento econômico encontraram grande resistência e virtualmente desapareceram entre o fim da década de 1960 e o final da década de 1980. No entanto, parcialmente devido ao trabalho de estudiosos como Inglehart e Putnam e em parte devido ao interesse renovado de vários policy-makers, as abordagens culturalistas retornaram ao centro do debate nos anos 1990. O surgimento recente de um volume entitulado Culture Matters (HARRISON \& HUNTINGTON, 2000) seria pouco provável em política comparada uma década atrás ${ }^{2}$. Muitos dos eminentes autores em Culture Matters (Samuel Huntington, Seymour Martin Lipset, David Landes, Jeffrey Sachs, Francis Fukuyama) trazem várias versões do argumento neoweberiano de que valores nacionais, idéias e configurações culturais influem fortemente nas probabilidades de desenvolvimento econômico.

E o desenvolvimento econômico, como notamos acima, continua o melhor preditor estatístico da corrupção em nível mundial. Lipset e Lenz (2000), em seu ensaio publicado em Culture Matters, oferecem uma explicação sucinta de por que esse deve ser o caso. Primeiramente, o desenvolvimento econômico pode "mudar a estrutura de incentivos dos funcionários públicos", o que sublinha a hipótese de Jackman e Montinola

2 Esse livro foi publicado no Brasil sob o título A cultura importa (Rio de Janeiro: Record, 2002).
(2002) de que o aumento dos salários no setor público diminuiria a corrupção. Em segundo lugar, Lipset e Lenz observam que "o custo da punição - encarceramento, ficha criminal, constrangimento, perda de empregos futuros - provavelmente aumenta com a renda". Em terceiro lugar, o aumento da riqueza nacional também estimula um aumento nos níveis educacionais e maiores níveis de instrução aumentam a possibilidade de identificar e punir a corrupção. Finalmente, os autores sugerem que "o desenvolvimento econômico também pode reduzir a corrupção por meio de seu impacto importante e positivo na democracia, o que, as evidências sugerem, reduz a corrupção" (LIPSET \& LENZ, 2000, p. 115). Essa observação final é oportuna porque nos lembra da relação causal entre nossas duas variáveis de controle, "desenvolvimento econômico" e "democracia", uma relação que Lipset foi um dos primeiros a identificar (LIPSET, 1959). Muitas pesquisas empíricas sugerem que a cultura tem um efeito independente tanto no desenvolvimento econômico como na democracia, mas que os dois fatores, por sua vez, afetam um ao outro de maneiras importantes.

Concluindo, há fortes razões para acreditar que os lagged effects da cultura estão parcialmente incorporados em nossas variáveis de controle principais, que juntas explicam $80 \%$ da variância nos níveis internacionais de corrupção percebida. Se esse é o caso, então é notável que diversos dos fatores culturais examinados nesse estudo, com destaque para a confiança interpessoal e para a filiação religiosa, terminaram por fornecer poder explicativo adicional acima e além dessas variáveis estruturais que já devem ter incorporado a cultura. Se esse não é o caso - isto é, se o leitor não aceita que os níveis contemporâneos de democracia e desenvolvimento incorporam efeitos culturais, e alternativamente preferem vê-los como controles ambientais neutros - então ainda é importante notar que a cultura parece proporcionar-nos ao menos alguma modesta vantagem analítica sobre o problema da corrupção. Em linhas gerais, nosso exame preliminar sobre a corrupção sugere que enquanto a cultura política pode não ser um fator tão decisivo como alguns de seus atuais proponentes proclamam (por exemplo, HARRISON \& HUNTINGTON, 2000), não há dúvidas de que a cultura e o capital social devem ter um papel em nossas investigações sobre democracia e desenvolvimento. 
Timothy J. Power (powertj@fiu.edu) é professor de Ciência Política na Florida International University (FIU) em Miami (EUA) e Presidente eleito da Brazilian Studies Association (http://www.brasa.org).

Júlio González (lgonza2312@aol.com) é doutorando em Ciência Política na FIU.

\section{REFERÊNCIAS BIBLIOGRÁFICAS}

ALMOND, G. \& VERBA, S. 1963. The Civic Culture : Political Attitudes and Democracy in Five Nations. Princeton : Princeton University Press.

BANFIELD, E. 1958. The Moral Basis of a Backward Society. New York : The Free Press.

CENTRAL INTELLIGENCE AGENCY. 2000. CIA World Factbook. Washington : CIA.

DELLAPORTA, D. \& VANNUCCI, A. 1999. Corrupt Exchanges : Actors, Resources, and Mechanisms of Political Corruption. New York : Aldine deGruyter.

DIAMOND, L. 1999. Developing Democracy: Toward Consolidation. Baltimore : Johns Hopkins University Press.

FREEDOM HOUSE. 2000. Press Freedom Survey 2000. Washington : Freedom House.

FUKUYAMA, F. 1995. Trust : The Social Virtues and the Creation of Prosperity. New York : The Free Press.

HARRISON, L. \& HUNTINGTON, S. (eds.). 2000. Culture Matters : How Values Shape Human Progress. New York : Basic Books.

HELLMAN, J., JONES, G. \& KAUFMANN, D. 2000. Seize the State, Seize the Day : An Empirical Analysis of State Capture and Corruption in Transition Economies. Paper presented at the Annual Congress of the ABCDE, Washington, D. C., 2000.

HESSEL, M. \& MURPHY, K. 2000. Stealing the State, and Everything Else : A Survey of Corruption in the Postcommunist World. London: The Transparency International Centre for Innovation and Research. http:// www.transparency.org/working_papers/ hessel. Acesso em : maio.2003.

HUNTINGTON, S. 1984. Will More Countries Become Democratic? Political Science Quarterly, New York, v. 99, n. 2, p. 193-218, Summer.
HUSTED, B. W. 1999. Wealth, Culture, and Corruption. Journal of International Business Studies, Houndmills (Hampshire), v. 30, n. 2, p. 339-360, June.

INGLEHART, R. 1977. The Silent Revolution: Changing Values and Political Styles Among Western Publics. Princeton : Princeton University Press.

. 1988, The Renaissance of Political Culture. American Political Science Review, Cambridge, v. 82, n. 4, p. 1203-1230, Nov.

. 1990. Culture Shift in Advanced Industrial Society. Princeton : Princeton University Press.

. Modernization and Postmodernization : Cultural, Economic, and Political Change in 43 Societies. Princeton : Princeton University Press.

. 2000a. Culture and Democracy. In : HARRISON, L. \& HUNTINGTON, S. (eds.). Culture Matters : How Values Shape Human Progress. New York : Basic Books.

.2000b. World Values Surveys and European Values Surveys. 1981-1984, 1990-1993, and 1995-1997 (Databank and Codebook). Study n. 2790. Michigan : Ann Arbor-Inter-University Consortium for Political and Social Research.

INKELES, A. \& SMITH, D. 1974. Becoming Modern : Individual Change in Six Developing Countries. Cambridge : Harvard University Press.

JACKMAN, R. \& MONTINOLA, G. 2002. Sources of Corruption : A Cross-Country Study. British Journal of Political Science, Colchester, v. 32, n. 1, p. 147-170, Jan.

JOHNSTON, M. 2000. The New Corruption Rankings : Implications for Analysis and Reform. Paper presented at the World Congress of the International Political Science Association, Quebec, Canada, from August $1^{\text {st }}$ to $5^{\text {th }} 2000$. 
KLITGAARD, R. 1988. Controlling Corruption. Berkeley : University of California Press. 1998. International Cooperation against Corruption. Finance and Development, Washington, D.C., v. 35, n. 1, p. 3-6. Mar.

KNACK, S. \& KEEFER, P. 1995. Institutions and Economic Performance : Cross-Country Tests Using Alternative Institutional Measures. Economics and Politics, Oxford, v. 7, n. 3, p. 207-227.

LAGOS, M. 1997. Latin America's Smiling Mask. Journal of Democracy, Baltimore, v. 8, n. 3, p. 125-138, July.

LAMBSDORFF, J. 2000a. Background Paper to the 2000 Corruption Perceptions Index : Framework Document. London : The Transparency International Centre for Innovation and Research. www.transparency.de/documents/cpi/2000/ methodology.html. Acesso em : maio.2000.

2000b. Background Paper to the 2000 Corruption Perceptions Index : The Precision and Regional Comparison of Perceived Levels of Corruption-Interpreting the Results. London : The Transparency International Centre for Innovation and Research. www.transparency.de/documents/cpi/2000/report.html. Acesso em : Maio.2000.

LA PORTA, R., LOPEZ-DE-SILANES, SHLEIFER, A.\& VISHNY, R. W. 1997. Trust in Large Organizations. American Economic Review, Nashville, v. 87, n. 2, p. 333-338, May.

. 1999. The Quality of Government. Journal of Law, Economics, and Organization, Oxford, v. 15, n. 1, p. 222-279, Mar.

LIPSET, M. 1959. Some Social Requisites of Democracy : Economic Development and Political Legitimacy. American Political Science Review, Cambridge, v. 53, n. 1, p. 69-105, Feb.

LIPSET, M. \& LENZ, G. 2000. Corruption, Culture, and Markets. In : HARRISON, L. \& HUNTINGTON, S. (eds.). Culture Matters : How Values Shape Human Progress. New York : Basic Books.

MULLER, E. \& SELIGSON, M. 1994. Civic Culture and Democracy : The Question of
Causal Relationships. American Political Science Review, Cambridge, v. 88, n. 3, p. 645652, Sept.

NDIAYE, K. 1998. Latin America : A Changing Reality. Finance and Development, Washington, D.C., v. 35, n. 1, p. 79-81. Mar.

NEWTON, K. 1999. Social and Political Trust in Established Democracies. In : NORRIS, P. (ed.). Critical Citizens : Global Support for Democratic Government. New York : Oxford University Press.

NORRIS, P. 1999. Conclusions : The Growth of Critical Citizens and Its Consequences. In : (ed.). Critical Citizens : Global Support for Democratic Government. New York : Oxford University Press.

PRZEWORSKI, A. 1991. Democracy and the Market. New York : Cambridge University Press.

PUTNAM, R. 1993. Making Democracy Work: Civic Traditions in Modern Italy. Princeton : Princeton University Press.

1995a. Bowling Alone: America's Declining Social Capital. Journal of Democracy, Baltimore, v. 6, n. 1, p. 65-78, Jan.

. 1995b. Tuning In, Tuning Out : The Strange Disappearance of Social Capital in America. PS : Political Science and Politics, Madison, v. 27 , n. 4 , p. $664-683$, Oct.

2000. Bowling Alone: The Collapse and Revival of American Community. New York : Simon and Schuster.

ROSE-ACKERMAN, S. 1999. Corruption and Government : Causes, Consequences, and Reform. New York : Cambridge University Press.

SCOTT, J. 1972. Comparative Political Corruption. Englewood Cliffs, NJ : PrenticeHall.

SELIGSON, M. 2002. The Impact of Corruption on Regime Legitimacy : A Comparative Study of Four Latin American Countries. Journal of Politics, Columbia (S. Carol.), v. 64, n. 2, p. 408-433, May.

SWAMY, A., LEE, Y., KNACK, S. \& AZFAR, O. 1999. Gender and Corruption. Working Paper n. 22. College Park : IRIS CenterUniversity of Maryland. 
TRANSPARENCY INTERNATIONAL. 2000. 2000 Corruption Perceptions Index. London : The Transparency International Centre for Innovation and Research. http://www.transparency.de/documents/cpi/2000/ cpi2000.html\#cpi. Acesso em : maio.2000.

TREISMAN, D. 1999. Decentralization and Corruption: Why Are Federal States Perceived To Be More Corrupt? Paper presented at the Annual Congress of the American Political Science Association, Atlanta, September.

2000. The Causes of Corruption : A CrossNational Study. Journal of Public Economics,
Saskatoon, v. 76, n. 3, p. 399-457, June.

UNITED NATIONS. 1999. Human Development Report. New York : Oxford University Press.

WEBER, M. 1958. The Protestant Ethic and the Spirit of Capitalism. New York : Scribners.

WERLIN, H. 1990. Political Culture and Political Change. American Political Science Review, Cambridge, v. 84, n. 1, p. 249-253, Feb.

WORLD BANK. 2000. World Development Report. Washington, D. C.: The World Bank. www.worldbank.org/poverty/wdrpoverty/ report/index.htm. Acesso em : maio 2000. 